\title{
Factors influencing treatment outcomes in tuberculosis patients in Limpopo Province, South Africa, from 2006 to 2010: A retrospective study
}

\author{
Authors: \\ Mohammed M. Gafar \\ Norman Z. Nyazema ${ }^{1}$ \\ Yoswa M. Dambisya ${ }^{1}$ \\ Affiliations: \\ ${ }^{1}$ Department of Pharmacy, \\ School of Health Sciences, \\ University of Limpopo, \\ South Africa

\section{Correspondence to:} \\ Yoswa Dambisya \\ Email: \\ yoswad@gmail.com

\section{Postal address:} \\ Private Bag X1106, Sovenga \\ 0727, South Africa

\section{Dates:} \\ Received: 21 Apr. 2013 \\ Accepted: 18 Aug. 2014 \\ Published: 27 Nov. 2014 \\ How to cite this article: \\ Gafar, M.M., Nyazema, \\ N.Z. \& Dambisya, Y.M., \\ 2014, 'Factors influencing \\ treatment outcomes in \\ tuberculosis patients in \\ Limpopo Province, South \\ Africa, from 2006 to 2010 : \\ A retrospective study', \\ Curationis 37(1), Art. \#1169, \\ 7 pages. http://dx.doi. \\ org/10.4102/curationis. \\ v37i1.1169

\section{Copyright: \\ (C) 2014. The Authors. Licensee: AOSIS OpenJournals. This work is licensed under the Creative Commons Attribution} \\ License.
}

Background: South Africa has a high burden of tuberculosis (TB), with high human immunodeficiency virus (HIV)-TB co-infection rates and the emergence of multidrugresistant TB.

Objectives: To describe treatment outcomes and factors influencing outcomes amongst pulmonary TB (PTB) patients in the Limpopo Province.

Method: A retrospective review was conducted of data on the provincial electronic TB register (ETR.net) for the years 2006 to 2010 (inclusive), and a random sample of 1200 records was selected for further analysis. The Chi square test was used to examine the influence of age, gender, health facility level, diagnostic category and treatment regimen on treatment outcomes.

Results: Overall 90617 (54.6\% male) PTB patients were registered between 2006 and 2010. Of the sampled $1200 \mathrm{~TB}$ cases, $72.6 \%$ were in persons aged 22 to 55 years and $86.2 \%$ were new cases. The TB mortality rate was $13.6 \%$ (much higher than the World Health Organization target of 3\%), whilst the default rate was $9.8 \%$. There was a strong association between age $(P<0.001)$, diagnostic category $(P<0.001)$, treatment regimen $(P<0.001)$, and health facility level $(P<0.001)$ and treatment outcome. Those aged $22-55$, and $56-74$ years were more likely to die $(P<0.05)$. Poor treatment outcomes were also associated with initial treatment failure, receiving treatment at hospital and treatment regimen II.

Conclusion: The poor TB treatment outcomes in Limpopo, characterised by a high mortality and default rates, call for strengthening of the TB control programme, which should include integration of HIV and/or AIDS and TB services.

\section{Introduction}

South Africa (SA) is ranked fifth amongst the 22 tuberculosis (TB) high burden countries in the world (World Health Organization (WHO) 2010), with nearly 460000 new TB cases in 2007, an incidence rate of 948 cases per 100000 population, and TB prevalence of 692 per 100000 (WHO 2009). Although TB is a notifiable disease in SA, the quality of notification and reporting varies. For instance, the case detection rate of smear-positive cases in 2007 for the directly observed treatment short-course (DOTS) programme was 78\% in SA, whilst the WHO advocates for rates higher than $85 \%$ (WHO 2009).

SA is faced with a high rate of TB and human immunodeficiency virus (HIV) co-infection as well. It is estimated that $60 \%$ of new TB cases are HIV-positive (WHO 2010; Chimbindi, Bärninghausen \& Newell 2013). The high burden of TB-HIV co-infection is compounded by emergence of high levels of multidrug-resistant TB (MDR-TB) and extensively drug-resistant TB, XDR- TB (Rawlison et al. 2001; Goldman, Plumley \& Laughon 2007), all of which have implications for treatment outcomes amongst TB patients.

Since the roll-out of DOTS in 1996, TB treatment outcomes have improved greatly amongst those who start treatment, and it has been reported that up to $84 \%$ of people who take TB and HIV treatment reportedly complete TB treatment (Davies et al. 1999; Gandhi et al. 2009). Mortality due to TB in HIV co-infected persons, however, remains high in rural SA (MacPherson et al. 2009). It has also been reported that a variety of demographic, social, lifestyle and clinical factors may contribute to death due to TB amongst people with or without HIV co-infection (Ciglenecki et al. 2007). The National Tuberculosis Control Programme (NTCP) attributes low TB cure rates in SA mainly to poor patient compliance (South African NTCP 2004).

Limpopo is one of provinces most affected by TB. One report showed that approximately $55 \%$ of TB patients in the province were HIV-positive (Statistics SA 2006), although even higher figures 
of TB-HIV co-infection have been reported in SA (Houlihan et al. 2010). The present study aimed at describing treatment outcomes and factors that influence treatment outcomes amongst pulmonary TB (PTB) patients registered on the electronic TB registry (ETR.net) between 2006 and 2010 (inclusive). The main question addressed was 'What are the treatment outcomes, and what influenced such outcomes, amongst PTB patients in Limpopo Province for the period 2006 to 2010?'

\section{Problem statement}

The number of TB cases in Limpopo Province increased from 6286 in 2000 to 22292 in 2009, and this was accompanied by poor TB treatment outcomes such as a cure rate of $62.4 \%$, defaulter rate of $7.6 \%$ and death rate of $9.2 \%$ in 2008 . Factors contributing to poor treatment outcomes, treatment failure, and treatment interruption have not been documented in Limpopo Province. Hence the present study investigated the implications of factors such as demographic factors (namely age and sex), diagnostic category, smear positivity, level of health facility and treatment regimens on TB treatment outcomes in the province.

\section{Aims of the study}

The study aimed to investigate the factors that influence PTB treatment outcomes in Limpopo Province.

\section{Research objectives}

The specific objectives were to describe treatment outcomes amongst PTB patients for the period 2006-2010, inclusive, in Limpopo Province, and to describe factors influencing treatment outcomes amongst PTB patients registered for the period 2006-2010, inclusive, in Limpopo Province.

\section{Research method and design Design}

This was a retrospective study that utilised data available in the provincial database for all patients with PTB between 2006 and 2010, inclusive. The ETR.net software is designed to generate various patient listings, including personal patient information, health facilities and standard quarterly and annual reports on case finding and treatment outcomes. The retrospective design was chosen due to its convenience and relatively low cost to execute (Hess 2004). In the present study it was possible to review data covering five years within a short time and at minimal cost.

\section{Context of the study}

The study was conducted within the Limpopo Province TB Control Programme which has decentralised services through a network of healthcare facilities. The programme maintains a central database (ETR.net), with inputs from all the facilities through district programme coordinators. The provincial programme in turn sends data to the NTCP for the national reports.

\section{Study population and sample}

All 90617 records for TB patients registered on ETR.net for the years 2006-2010 were accessed, and of those $59967 \mathrm{had}$ complete records with a confirmed diagnosis of PTB. From the confirmed PTB cases, a sample size of 1200 was determined with guidance from a statistician. The main considerations in reaching the sample size were: (1) determination of the minimum representative sample size $(n=382)$ required (Krejcie \& Morgan 1970); (2) the need to stratify the sample across the 5 years under review to provide sufficient power for the study; and (3) the different variables to be considered.

Given the need to explore a number of variables (for instance treatment regimens, gender, diagnostic category), a sample much higher than the minimum was deemed necessary; the final sample included at least 174 samples per year. The sample $(n=1200)$ was stratified into the 5 years under review proportionally to the annual number of cases, as shown in Table 1. The stratified sample of 1200 records was then selected randomly from the total of 59967 confirmed PTB cases using the Statistical Package for Social Sciences (SPSS, version 20).

The cases included in the study were diagnosed by sputum smear test, received anti-TB treatment, and had the treatment outcomes recorded. Excluded were records for patients without the final treatment outcome, those with extrapulmonary $\mathrm{TB}$, those on second-line TB treatment, and those who died prior to starting treatment.

\section{Data collection method}

From the ETR.net database (ETR.net 2010), the option of 'patients in record' was used to extract patient record details including year of registration, gender, age, diagnostic category, health facility type, treatment regimen, confirmation of diagnosis and final treatment outcomes, but excluding the names and identity numbers to ensure anonymity of the patients. The treatment regimens were: regimen 1 , a six-month regimen for adults -2 months of rifampicin (R), isoniazid $(\mathrm{H})$, pyrazinamide $(\mathrm{Z})$ and ethambutol $(\mathrm{E})$, and rifampicin and isoniazid for 4 months (designated 2RHZE + $4 \mathrm{RH}$ ); regimen 2 over eight months, including streptomycin (S) for the first 3 months - 3RHZES + 5RHE; and regimen 3, over 6 months, for children, excluding ethambutol - 2RHZ + $4 \mathrm{RH}$. The ETR.net records did not, however, include linked data on HIV (such as HIV status, CD4+ counts, anti-retroviral therapy (ARV) and cotrimoxazole preventive therapy (CPT)

TABLE 1: Sampling frame for the 1200 cases.

\begin{tabular}{|c|c|c|c|c|c|}
\hline \multirow[t]{2}{*}{ Year } & \multirow[t]{2}{*}{ All records } & \multicolumn{2}{|c|}{ Complete PTB records } & \multicolumn{2}{|c|}{ Sample size } \\
\hline & & $N$ & $\%$ & $N$ & $\%$ \\
\hline 2006 & 12782 & 8839 & 9.2 & 174 & 14.8 \\
\hline 2007 & 14902 & 11026 & 4 & 221 & 18.4 \\
\hline 2008 & 18074 & 13818 & 6.5 & 285 & 23.0 \\
\hline 2009 & 22721 & 17074 & 5.1 & 344 & 28.4 \\
\hline 2010 & 22138 & 9210 & 41.6 & 176 & 15.4 \\
\hline Total & 90617 & 59967 & 74.5 & 1200 & 100 \\
\hline
\end{tabular}

PTB, pulmonary TB. 
interventions); however, it included global data on HIV in the form of quarterly and annual reports (ETR.net 2010).

\section{Data analysis}

The sampled dataset was imported into Microsoft Excel (version 2010) to ease preliminary data management and from there to SPSS (version 21) for analysis. This was on account of the fact that it was not possible, with the versions of ETR. net and SPSS that we were using, to import the ETR.net data directly into SPSS. Descriptive statistics were generated for the gender, age, diagnostic patient categories, TB treatment regimen, and treatment outcomes. The Chi square test was used to test the association between treatment outcome and different demographic and clinical variables, with the limit of significance at $P<0.05$, whilst the Z-test (post hoc Bonferroni method) was used to identify the variable categories that were significantly different at $P<0.05$.

\section{Results \\ Patient characteristics}

The total number of patient records for the period under review was 90617 (54.6\% male), out of which there were 59967 complete PTB cases for the purposes of the study. As shown in Table 1, more than half of the cases for 2010 were yet to be updated to include the treatment outcomes. Of the 1200 PTB cases sampled, 656 (54.7\%) were in males, whilst $544(45.3 \%)$ were in females. Most of them fell within the age group $22-55$ years $(n=871 ; 72.5 \%)$. Figure 1 shows the age distribution for the sample. The male-female distribution was similar within the different age groups in sample.

The majority of cases $(N=1035,86.2 \%)$ were new cases, and $962(80.1 \%)$ received treatment regimen I. Amongst the retreatment cases $(n=165), 52(31.5 \%)$ returned after defaulting, $39(23.6 \%)$ returned after failed treatment,

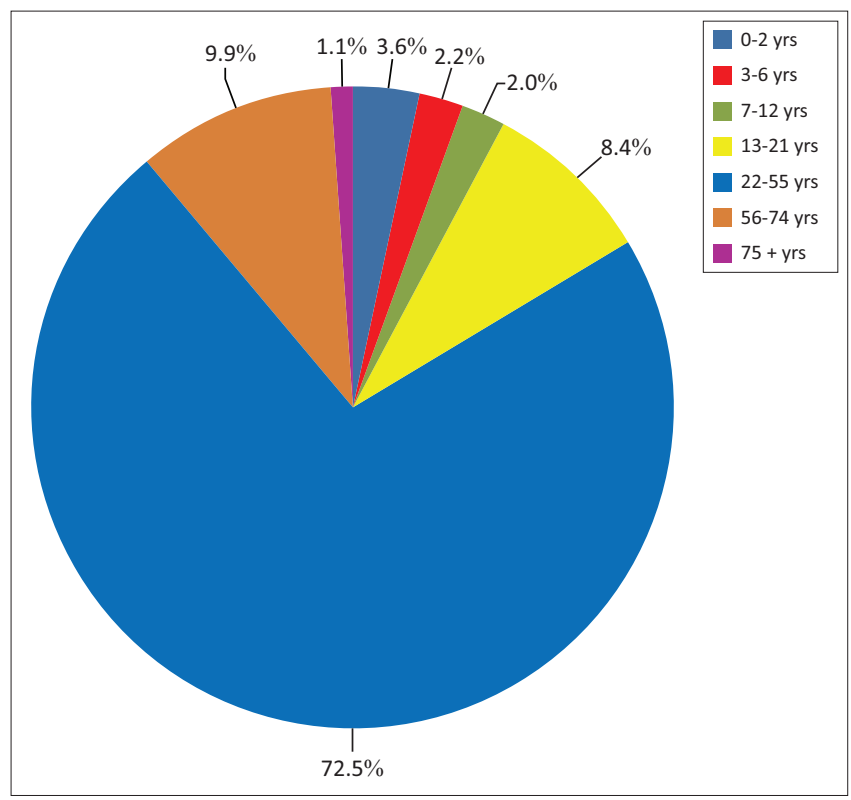

FIGURE 1: Age distribution of the sampled cases.
$62(37.5 \%)$ after relapse and $12(7.2 \%)$ returned for treatment for 'other' reasons. Most of the patients that required retreatment were also aged $22-55$ years.

\section{Treatment outcomes}

Results obtained regarding treatment outcomes showed that in $893(74.4 \%)$ cases treatment was successful, $118(9.8 \%)$ defaulted on treatment, whilst $26(2.2 \%)$ had treatment failure. The mortality rate amongst TB patients between 2006 and 2010 was found to be $13.6 \%(n=163)$. The respective percentages of those that died were: $10.3 \%$ in $2006,13.1 \%$ in $2007,11.2 \%$ in $2008,14 \%$ in 2009 and $20.5 \%$ in 2010 . Relatively more of those aged 2 years or younger (14\%), those aged $22-55$ years $(15 \%)$ and those aged 56 or more $(16.5 \%)$ were likely to die than the other age groups $(P<0.05)$. The influence of age on treatment outcomes is summarised in Table 2.

\section{Determinants of treatment outcomes}

There was a strong association between age $(P<0.001)$, diagnostic category $(P<0.005)$, treatment regimen $(P<$ $0.005)$, and health facility level $(P<0.001)$ on the one hand, and treatment outcome on the other. Patients aged 3-6 years, plus those that were diagnosed as new cases, those that received treatment at mine health facilities or those that were treated with regimen III $(2 \mathrm{RHZ}+4 \mathrm{RH})$ had more successful treatment outcomes $(P<0.001)$. On the other hand, patients in the age range 7-12 years, and those in the 22-55-year age range, patients with a history of defaulting, and those that received treatment at a community health centre or village health facilities were more likely to default on their treatment $(P<0.05)$. Those that fell within age group 22-55 or 56-74 years, those that had initial treatment failure, that received treatment at hospital or mobile health facilities or were treated with regimen II (3RHZES + 5 RHE) experienced treatment failure more often $(P<0.05)$. A summary of the influence of treatment regimens on treatment outcomes is presented in Table 3.

ETR.net data does not include HIV data linked to specific TB patients (there was no HIV-positive TB patient category identifiable as such), but generates integrated TB-HIV summaries for specified time periods. The testing rate for HIV amongst TB patients increased from less than $1 \%$ in 2006 to $68.0 \%$ in 2010, and the number of TB patients known to be HIV-positive rose from 5 in 2006 to 10531 (47.6\%) in 2010. The number of patients requiring and receiving ART also increased during the period under review, as shown in Table 4. Evidently the integration of TB and HIV services improved greatly during the period under review.

ETR.net data included facilities by name and not by facility level, and the facility level/type could be established in only 376 of the cases sampled. The trends showed that those treated at mine facilities had the highest treatment success rates and lowest default and treatment failure rates (Figure 2). The hospitals, on the other hand, had the highest death rates and the lowest success rates, whilst those treated 
TABLE 2: Influence of age on treatment outcomes.

\begin{tabular}{|c|c|c|c|c|c|c|c|c|c|c|c|}
\hline \multirow{3}{*}{$\begin{array}{l}\text { Age } \\
\text { Group (years) }\end{array}$} & \multicolumn{11}{|c|}{ Treatment outcome } \\
\hline & \multicolumn{2}{|c|}{ Successful } & \multicolumn{2}{|c|}{ Unsuccessful } & \multicolumn{2}{|c|}{ Defaulted } & \multicolumn{2}{|c|}{ Failed } & \multicolumn{2}{|c|}{ Died } & \multirow[t]{2}{*}{ Total } \\
\hline & $n$ & $\%$ & $n$ & $\%$ & $n$ & $\%$ & $n$ & $\%$ & $n$ & $\%$ & \\
\hline $0-2$ & 36 & 83.7 & 7 & 16.3 & 1 & 2.3 & 0 & 0.0 & 6 & $14 *$ & 43 \\
\hline $3-6$ & 23 & $92 *$ & 2 & 8 & 1 & 4 & 0 & 0.0 & 1 & 4 & 25 \\
\hline $7-12$ & 22 & 1.5 & 5 & 18.5 & 4 & $14.8^{*}$ & 0 & 0.0 & 1 & 3.7 & 27 \\
\hline $13-21$ & 90 & 9.1 & 11 & 10.9 & 8 & 7.9 & 1 & 1 & 2 & 2 & 101 \\
\hline $22-55$ & 619 & 71.2 & 252 & $28.9 *$ & 101 & $11.6^{*}$ & 20 & $2.3^{*}$ & 131 & $15^{*}$ & 871 \\
\hline $56-74$ & 27 & 77.3 & 27 & 22.7 & 2 & 1.7 & 5 & $4.2^{*}$ & 20 & $16.8^{*}$ & 119 \\
\hline $75+$ & 3 & 78.6 & 3 & 21.4 & 1 & 7.1 & 0 & 0.0 & 2 & 14.4 & 14 \\
\hline Total & 893 & 74.4 & 307 & 25.6 & 118 & 9.8 & 26 & 2.2 & 163 & 13.6 & 1200 \\
\hline
\end{tabular}

$X^{2}=91.882, \mathrm{df}=24$.

$p<0.001 ;{ }^{*} p<0.05$ (Bonferroni method)

TABLE 3: Treatment regimen versus outcome amongst 1200 PTB cases.

\begin{tabular}{|c|c|c|c|c|c|c|c|c|c|c|c|}
\hline \multirow[t]{3}{*}{ Regimen } & \multicolumn{10}{|c|}{ Treatment outcome } & \multirow{3}{*}{ Total } \\
\hline & \multicolumn{2}{|c|}{ Successful } & \multicolumn{2}{|c|}{ Unsuccessful } & \multicolumn{2}{|c|}{ Defaulted } & \multicolumn{2}{|c|}{ Failed } & \multicolumn{2}{|c|}{ Died } & \\
\hline & $n$ & $\%$ & $n$ & $\%$ & $n$ & $\%$ & $n$ & $\%$ & $n$ & $\%$ & \\
\hline Regimen I & 724 & 75.3 & 238 & 24.7 & 96 & 10 & 17 & 1.8 & 125 & 13 & 962 \\
\hline Regimen II & 100 & 2.9 & 59 & $37.1 *$ & 19 & 11.9 & 9 & $5.7^{*}$ & 31 & $19.5 *$ & 159 \\
\hline Regimen III & 69 & $7.3^{*}$ & 10 & 12.7 & 3 & $3.8^{*}$ & 0 & 0.0 & 7 & 8.9 & 79 \\
\hline Total & 893 & 74.4 & 307 & 25.6 & 118 & 9.8 & 26 & 2.2 & 163 & 13.6 & 1200 \\
\hline
\end{tabular}

PTB, pulmonary TB

$X^{2}=72.328, \mathrm{df}=8$

$p<0.001 ; * p<0.05$ (Bonferroni method)

TABLE 4a: Testing rate, smear positivity amongst HIV-positive TB patients, 2006-2010.

\begin{tabular}{|c|c|c|c|c|c|c|c|c|}
\hline \multirow[t]{2}{*}{ Year } & \multicolumn{5}{|c|}{ HIV-positive } & \multicolumn{2}{|c|}{ Tested for HIV } & \multirow[t]{2}{*}{ Total patients } \\
\hline & Smear +ve & Smear -ve & Smear not done & Extra-pulmonary TB & $\begin{array}{c}\text { Total } \\
\text { (\% of patients) }\end{array}$ & $n$ & $\%$ & \\
\hline 2006 & 2 & 1 & 2 & - & $5(0.04 \%)$ & 5 & 0.04 & 12782 \\
\hline 2008 & 1362 & 379 & 698 & 373 & $2812(15.6 \%)$ & 4237 & 23.4 & 18074 \\
\hline 2009 & 2874 & 966 & 1191 & 1031 & $6062(26.7 \%)$ & 8758 & 38.5 & 22721 \\
\hline 2010 & 4514 & 2193 & 1670 & 2154 & $10531(47.6 \%)$ & 15049 & 68.0 & 22138 \\
\hline
\end{tabular}

TABLE 4b: ART and CPT amongst HIV-positive TB patients, 2006-2010.

\begin{tabular}{|c|c|c|c|c|c|c|c|c|}
\hline \multirow[t]{2}{*}{ Year } & \multicolumn{2}{|c|}{ CD4 count not done } & \multicolumn{2}{|c|}{ Eligible patients on ART } & \multicolumn{2}{|c|}{ Eligible patients not on ART } & \multicolumn{2}{|c|}{ Eligible patients on $\mathrm{CPT}$} \\
\hline & $n$ & $\%$ & $n$ & $\%$ & $n$ & $\%$ & $n$ & $\%$ \\
\hline 2006 & 5 & - & - & - & - & - & - & - \\
\hline 2007 & 330 & 97.6 & 34 & 10.1 & 184 & 54.4 & - & 1.5 \\
\hline 2008 & 1922 & 68.3 & 504 & 17.9 & 662 & 23.5 & 1800 & 64 \\
\hline 2009 & 2952 & 48.7 & 1653 & 27.3 & 2223 & 36.7 & 4867 & 80.3 \\
\hline 2010 & 4582 & 43.5 & 3726 & 35.4 & 4101 & 38.9 & 8998 & 81.6 \\
\hline
\end{tabular}

CPT, cotrimoxazole preventive therapy; ART, anti-retroviral therapy.

at community health centres and clinics were the most likely to default. As indicated above, the differences in outcome were statistically significant $(P<0.001)$, and this remained true even when the 'facility unstated' category was included in the analysis $(P<0.05)$.

\section{Ethical considerations}

Ethical clearance was granted by the University of Limpopo Medunsa Campus Research Ethics Committee, and in addition approval for the study and permission to access the ETR.net data were obtained from the Limpopo Provincial Research Committee and Limpopo Province TB Control Programme respectively. This study was based on retrospective data, therefore no patients were seen, and there was no disruption of service delivery or inconvenience at the facilities as only data available on the provincial database were used. Patient information was captured anonymously, and confidentiality was observed for all the data obtained. Access to ETR.net was under the direct control of the Provincial Department of Health TB Control Programme officers, and all information obtained was used only for this study.

\section{Trustworthiness}

\section{Validity and reliability}

The sample size was determined using Krejcie and Morgan's (1970) table as 382 cases from the 59967 complete PTB records. In order to improve the power of the study with stratification of the sample into the 5 years, a larger sample size was used (1200 records). The sample was chosen randomly using the 


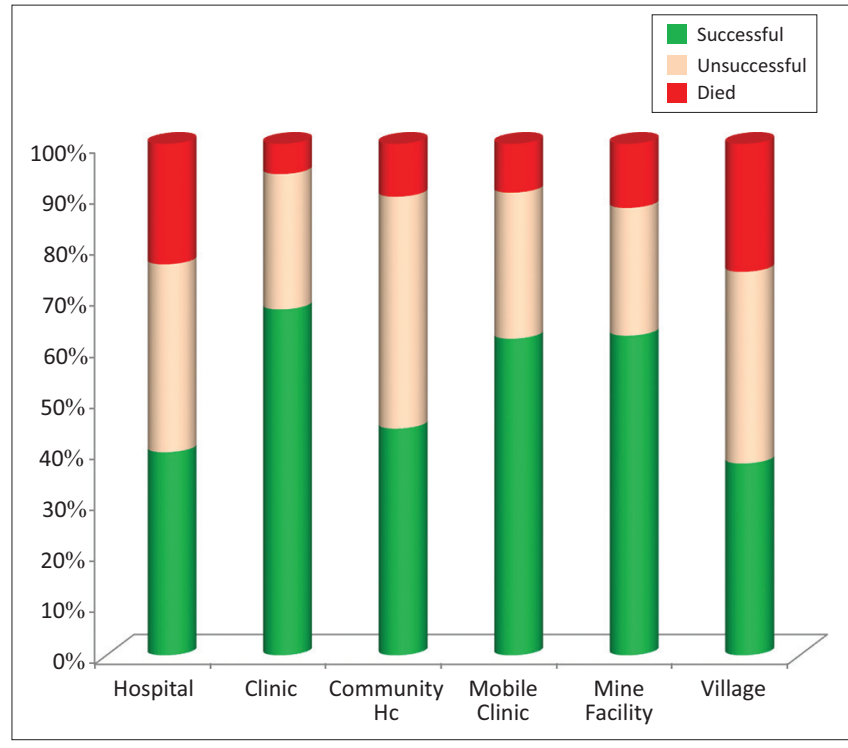

There were relatively more deaths amongst those treated at hospitals and village facilities, whilst there was relatively more successful treatment at mine facilities, mobile clinics and PHC clinics.

FIGURE 2: Treatment facility versus Treatment outcomes.

SPSS programme, so no bias was involved in selection of the sample records. Results from the sample analysis were compared to some of the summary statistics from the whole study population (complete records for 2006-2010) and found to be similar; for instance, the sex distribution was the same for both the sample and population.

The data collection template was based on available data on ETR.net, and the research team cross-checked the values obtained from the preliminary sample analysis to ensure accuracy. Analysis was guided by the statistician and aided by an understanding and working knowledge of the statistical package.

\section{Discussion}

The majority of TB cases in Limpopo Province were in the economically productive age group (22-55 years, $72.6 \%$ of cases). That is similar to the findings of a study from Malaysia where TB was found to be most prevalent amongst the same age range (Nik et al. 2011). The high prevalence of TB in this age group may be due to the fact that those aged $22-55$ years account for $58 \%$ of the total population of Limpopo Province (Statistics SA 2006), which suggests that the high number is proportional to the contribution of that age group to the base population in the province. In addition, this is the sexually active age group and those most at high risk for HIV and/or AIDS, with a high risk of TB-HIV co-infection (Houlihan et al. 2010; Abdool-Karim et al. 2009; Lawn et al. 2006).

\section{TB-HIV co-infection}

The high numbers of TB cases amongst this age group may partly be a manifestation of the high HIV infection rate and high TB-HIV co-infection. There was, however, no directly linked HIV-related data available in this study, that is it was not possible to identify which of the patients had TB-HIV co-infection; what was available were only summarised data with the trends alluded to above. Thus it was possible to obtain the number and/or proportion of TB patients who tested for HIV, those who tested HIV-positive and those who were on ART or CPT, but not who the particular patients were. The ETR.net program is so designed that all HIV data are concealed, to ensure the confidentiality of the individual patient whilst providing summarised data on trends. The limited data available on HIV infection indicated that in 2006-2010 there was an increase in the number of TB patients who were tested for HIV, an increase in the number of HIV-TB co-infected patients that received ART, and an increase in the number of TB-HIV co-infected patients who received CPT.

The large number of TB patients not tested for HIV (32\% in 2010) and the large numbers of HIV-positive patients who did not have CD4 counts done are cause for concern, given the documented benefits of providing ART to eligible TB patients (Tabrasi et al. 2009; Davies et al. 1999). It is important to establish the HIV status and CD4 count to guide the decision to start ART in the TB patient (Ghandi et al. 2009; Houlihan et al. 2010). The increase in HIV services for TB patients did not translate into any definite improvements in treatment outcomes across the years - for instance, death rates were $10.3 \%$ in 2006 rising to $14 \%$ in 2009 . The case mortality rate for 2010 was even higher $(20.5 \%)$, but it must be borne in mind that many records for 2010 were excluded from the study due to lack of treatment outcomes. Interpretation of the rising mortality rate amongst TB patients on treatment between 2006 and 2010 was not possible since the study sample could not be disaggregated to obtain the treatment outcomes for HIV-positive patients.

A previous report on global TB control showed that TB treatment success rates varied from $60 \%$ in Uganda to $93 \%$ in China, with an average of $83 \%$ (WHO 2005). The current study found that the success of treatment of TB was at a relatively acceptable $73.3 \%$, which is similar to the South African national success rate for 2006 (South African National Tuberculosis Association 2008), although it is below the WHO target of $85 \%$. Patients that received regimen II were more likely to experience treatment failure than those treated with regimen 1 . Those on regimen II were retreatment cases, and retreatment TB cases treated with standard regimen II have been reported to have poorer outcomes, including higher risk of development of MDR-TB (WHO 2004; Quy et al. 2006). Moreover, retreatment with regimen II has not been systemically evaluated for effectiveness (López et al. 2011).

It was also observed in the current study that cases diagnosed as 'other' - defined by the WHO as those TB patients who have negative smear test or who are HIV-positive (WHO 2005) - were more likely to have successful treatment outcomes than retreatment cases. That is consistent with a study conducted in India, which found that TB categorised as 'others' and treated with a category II regimen had better outcomes compared to relapse, failure and retreatment after default (Srinath et al. 2011). 


\section{Default rates}

In this study the default rate was $9.8 \%$, which is approximately double the international target of less than $5 \%$. $t$ is plausible that the high default rate amongst the 22-55-year age group may be explained by high HIV and/or AIDS rates, as TB and/or HIV co-morbidity is amongst the condition-related factors reported as predictors of TB treatment default (Dodor \& Afenyadu 2005; Jaiswal et al. 2003; Tabrasi et al. 2009). However, there have been other studies that found no association between HIV and/or AIDS and TB treatment default rates (Amoran, Osiyale \& Lawal 2011; Makombe et al. 2007), which suggests that there may have been other factors which contributed to that high default rate. It was one of the limitations of the present study that the database did not include information on social variables which are known to contribute to adherence to treatment (Amoran et al. 2011; Burton et al. 2011).

\section{TB mortality}

The overall death rate in Limpopo Province amongst TB patients was $13.6 \%$, which is much higher than the WHO target rate of 3\% (Veen et al. 1998). The apparent deterioration of survival over the years (death rates rose from $10.3 \%$ in 2006 to $20.5 \%$ between 2006 and 2010) may be attributed to the increased prevalence of HIV and/or AIDS and MDRTB which paralleled the TB incidence (National Institute for Communicable Diseases \& National Health Laboratory Services 2010).

The high mortality rate amongst the under-two-yearolds and those in the 22-55-years age group may also be attributed to the high prevalence of HIV infection amongst these groups, as the association between HIV infection and TB mortality has been reported by several studies (e.g. Anunnatsiri et al. 2005; Burton et al. 2011), whilst high mortality amongst the older age group (56 years and older) may be attributed to advanced age, with higher likelihood of co-morbidities (Falzon et al. 2005; PerezGuzman et al. 1999).

\section{Limitations of the study}

There was a lack of linked HIV data, and the inferences regarding TB-HIV co-infection were based on summary data. Consequently it was not possible to attribute any of the outcomes to HIV status, and it was not evident from available information which patients had taken what other medications for any other co-morbidities. The ETR.net system does not capture socio-economic data; hence it was not possible to attribute treatment outcomes to factors such as support from family, employment status or income (Ai et al. 2010). It should also be borne in mind, however, that not all patients registered in 2010 had the outcome data recorded at the time the study was conducted. It is possible that many patients that subsequently had successful treatment outcomes were excluded from the study due to incomplete data at the time of the study.

\section{Recommendations}

Notwithstanding those reservations, our findings throw some light on the profile of TB patients and their outcomes in the Limpopo Province, and point to some of the associations deserving attention in the TB control efforts, including the following:

1. There is a need to upgrade the ETR.net data capture template to include crucial information, for instance on HIV and social status, that will help programmatic improvements from that otherwise rich database.

2. There is a need to strengthen the DOTS programme to reduce chances of treatment failure and the need for retreatment, as patients on retreatment tend to have poorer treatment outcomes.

3. Efforts towards integration of HIV-TB services and reporting should be strengthened.

\section{Conclusion}

TB treatment outcomes are poor in Limpopo Province, particularly amongst patients with a previous history of TB treatment, those receiving treatment in hospitals, or those being treated with first-line regimen II, which calls for strengthening of the NTCP towards more effective responses, for instance through integrated HIV and TB services and reporting. Further studies are needed to address the effect of HIV status and AIDS, CD4+ cell counts, ART, CPT and radiological presentation, and their effect on $\mathrm{TB}$ treatment outcome in Limpopo Province.

\section{Acknowledgements}

The authors wish to thank Dr Tiyani Mabunda and all the staff of the Limpopo Province TB Control Programme for their cooperation during the study, and Mr Victor Netshidzivhani, research statistician, for his guidance in the design of the study and analysis of the data. M.M.G. was a postgraduate student supported by the Medical Services Department of the Ministry of Defence, Republic of Sudan.

\section{Competing interests}

The authors declare that they have no financial or personal relationship(s) that may have inappropriately influenced them in writing this article.

\section{Authors' contributions}

All authors (M.M.G., N.Z.N. and Y.M.D., all of the University of Limpopo) contributed to the conception, design and conducting of the study, and analysis of the data. M.M.G. collected the data, carried out the preliminary analysis and drafted the manuscript. N.Z.N. made inputs into the data capture exercise and analysis and revised the draft manuscript. Y.M.D. provided overall guidance, helped finalise the study protocol and data collection template, obtained permission to utilise the provincial ETR.net data, supervised data analysis and commented on the initial draft of 
the manuscript. Both N.Z.N. and Y.M.D. reviewed and revised the manuscript prior to submission. All authors reviewed the final manuscript and consented to its publication.

\section{References}

Abdool-Karim, S.S., Churchyard, G.J., Abdool-Karim, Q. \& Lawn, S.D., 2009, 'HIV infection and tuberculosis in South Africa: An urgent need to escalate the public health response,' Lancet 374 (9693), 921-933. http://dx.doi.org/10.1016/S01406736(09)60916-8

Ai, X., Men, K., Guo, L., Zhang, T. \& Zhaoy, Y., 2010, 'Factors associated with low cure rate of tuberculosis in remote poor areas of Shaanxi Province, China: A case control study,' BMC Public Health 10, 112.0:112.

Amoran, O., Osiyale, O. \& Lawal, K., 2011, 'Pattern of defaulting among TB patients on DOTS in rural primary health care centres in Ogun state,' Journal of Infectious Diseases and Immunity 3, 90-95.

Anunnatsiri, S., Chetchotisakd, P. \& Wanke, C., 2005, 'Factors associated with treatment outcomes in pulmonary tuberculosis in north eastern Thailand,' South East Asian Journal of Tropical Medicine and Public Health 36, 324-330.

Burton, N., Forson, A., Lurie, M., Kudzawu, S., Kwarteng, E. \& Kwara, A., 2011 'Factors associated with mortality and default among patients with TB attending
a teaching hospital clinic in Accra, Ghana,' Transactions of the Royal Society of a teaching hospital clinic in Accra, Ghana, Transactions of the Royal Society of
Tropical Medicine and Hygiene 105, 675-682. http://dx.doi.org/10.1016/j. Tropical Medicine
trstmh.2011.07.017

Chimbindi, N., Bärnighausen, T. \& Newell. M.-L., 2013, 'An integrated approach to improving the availability and utilization of tuberculosis healthcare in rural South Africa,' South African Medical Journal 103, 237-240. http://dx.doi.org/10.7196/ Africa,' South
samj.6423

Ciglenecki, I., Glynn, J., Mwinga, A., Ngwira, B., Zumla, A., Fine, P.E.M. \& Nunn, A., 2007, 'Population differences in death rates in HIV positive patients with tuberculosis,' International Journal of Tuberculosis and Lung Diseases 11, 1121- 1128.

Davies, G., Connolly, C., Sturm, A., McAdam, K. \& Wilkinson, D., 1999, 'Twiceweekly, directly observed treatment for HIV-infected and uninfected tuberculosis patients: Cohort study in rural South Africa, AIDS 13, 811-817. http://dx.doi. org/10.1097/00002030-199905070-00010

Dodor, E.A. \& Afenyadu, G.Y., 2005, 'Factors associated with TB treatment default and completion at the Effia- Nkwanta Regional Hospital in Ghana,' Transaction of the Royal Society of Tropical Medicine and Hygiene 99, 827-832. http://dx.doi. org/10.1016/j.trstmh.2005.06.011

ETR.Net Report, Limpopo Province, 2010, viewed 16 April 2014, from www.etrnet.info

Falzon, D., Le Strat, Y., Belghiti, F. \& Infuso, A., 2005, 'Euro TB Correspondents: Exploring the determinants of treatment success for tuberculosis cases in Europe, International Journal of Tuberculosis and Lung Diseases 9, 1224-1229.

Gandhi, N.R., Moll, A.P., Lalloo, U., Pawinski, R., Zeller, K., Moodley, P. et al. 2009, 'Successful integration of tuberculosis and HIV treatment in rural South Africa:
The Siyanq'oba Study,' Journal of Acquired Immune Deficiency Syndromes 50, The Siyanq'
37-43. doi:

Goldman, R.C., Plumley, K.V. \& Laughon, B.E., 2007, 'The evolution of extensively drug resistant tuberculosis (XDR-TB): History, status and issues for global control,' drug resistant tuberculosis (XDR-TB): History, status
Infectious Disorders and Drug Targets 7, 73-91.

Hess, D.R., 2004, 'Retrospective studies and chart reviews,' Respiratory Care 49 (10), 1171-1174.

Houlihan, C.F., Mutevedzi, P.C., Lessells, R.J., Cooke, G.S., Tanser, F.C. \& Newell, M.L., 2010, 'The tuberculosis challenge in a rural South African HIV programme,' $B M C$ Infectious Diseases 10, 23. http://dx.doi.org/10.1186/1471-2334-10-23

Jaiswal, A., Singh, V., Ogden, J.A., Porter, J.D.H., Sharma, P.P., Sarin, R., Arora, V.K. \& Jain, R.C., 2003, 'Adherence to tuberculosis treatment: Lessons from the urban setting of Delhi, India,' Tropical Medicine and International Health 8, 625-633. http://dx.doi.org/10.1046/j.1365-3156.2003.01061.x

Krejcie, R.V. \& Morgan, D.W., 1970, 'Determining sample size for research activities,' Educational and Psychological Measurement 30, 607-601.
Lawn, S.D., Myer, L., Bekker L.G. \& Wood R., 2006, 'Burden of tuberculosis in an antiretroviral treatment programme in sub-Saharan Africa: Impact on treatment outcomes and implications for tuberculosis control,' AIDS 2006, 20:1605-1612. http://dx.doi.org/10.1097/01.aids.0000238406.93249.cd

López, E., Ayakaka, I., Levin, J., Reilly, N. \& Mumbowa F., 2011, 'Effectiveness of the standard WHO recommended retreatment regimen (category ii) for tuberculosis in Kampala, Uganda: A prospective cohort study,' PLOS Medicine 8(3). e1000427. $\mathrm{http}: / /$ dx.doi.org/10.1371/journal.pmed.1000427

MacPherson, P., Moshabelam, M., Martinson, N. \& Pronyk, P., 2009, 'Mortality and loss to follow up among highly active anti-retroviral therapy (HAART) initiators in rural South Africa,' Transactions of the Royal Society of Tropical Medicine and Hygiene 103, 588-599. http://dx.doi.org/10.1016/j.trstmh.2008.10.001

Makombe, S.D., Harries, A.D., Yu, J.K., Hochgesang, M., Mhango, E., Weigel, R. et al. 2007, 'Outcomes of tuberculosis patients who start antiretroviral therapy under routine programme conditions in Malawi,' International Journal of Tuberculosis and Lung Diseases 11, 412-416.

National Institute for Communicable Diseases \& National Health Laboratory Services, 2010, Communicable Diseases Surveillance Bulletin 8, No. 4, National Institute for Communicable Diseases \& National Health Laboratory Services, Pretoria.

Nik, N., Mohod, N., Wan, Z., Sharina, D. \& Nik, H., 2011, 'Factors associated with unsuccessful treatment outcome of TB in Kota Bharu, Kelantan,' Malaysian Journal of Public Health and Medicine 11, 6-15.

Perez-Guzman, C., Vargas, M., Torres-Cruz, A. \& Villarreal-Velarde, H., 1999, 'Does aging modify pulmonary tuberculosis? A meta-analytical review,' Chest 116 , 961-967. http://dx.doi.org/10.1378/chest.116.4.961

Quy, H., Buu, T., Lan, N., Cobelen, F., Borgdorff, M. \& Lambregts, K., 2006, 'Treatment outcome by drug resistance and HIV status among smear positive TB patients in Ho Chi Minh City, Vietnam, 1998-2000,' International Journal of Tuberculosis and Lung Diseases 10, 160-166.

Rawlison, J., Klaasen, S., Bamford, L. \& Visser, R., 2001, Improving management of patients with multi-drug resistant tuberculosis in lower orange district and Northern Cape province: Guideline for implementation of DOTS plus in context of South African TB control programmed: A system approach, Health Systems Trust, South Africa
Durban.

South African National Tuberculosis Control Programme, 2004, Practical Guidelines, viewed 12 April 2013, from http://www.kznhealth.gov.za/chrp/documents/ Guidelines/Guidelines $\% 20$ National/Tuberculosis/SA\%20TB\%20Guidelines $\% 20$ 2004.pdf

South African National Tuberculosis Association, 2008, Minister's Speech; Delivered at SANTA Provincial Conference 10th - 12th July 2008, viewed 12 February 2013, from http://www.dhsd.Limpopo.gov.za\docs \speech

Srinath, S., Sharath, B., Santosha, K., Chadha, S. \& Roopa, S., 2011, 'Tuberculosis 'retreatment others': Profile and treatment outcomes in the state of Andhra Pradesh, India,' International Journal of Tuberculosis and Lung Diseases 15, 105-109.

Statistics South Africa, 2006, Limpopo Province: Provincial profile (2004): Limpopo (Report No. 00-91-09), Statistics South Africa, Pretoria.

Tabrasi, P., Saber-Tehrani, A., Baghaei, P., Padyab, M., Mansouri, D., Amiri, M. et al., 2009, 'Early initiation of anti-retroviral therapy results in decreased morbidity and mortality among patients with TB and HIV,' Journal of the International AIDS Society 12, 14. http://dx.doi.org/10.1186/1758-2652-12-14

Veen, J., Raviglione, M., Rieder, H., Migliori, G., Graf, P., Grzemska, M. \& Zalesky, R., 1998, Standardized tuberculosis treatment outcome monitoring in Europe, European Respiratory Journal 12, 505-510. http://dx.doi.org/10.1183/0903193 6.98.12020505

World Health Organization, 2004, Treatment of Tuberculosis: Guideline for Nationa Programmes, 3rd edn., World Health Organization, Geneva.

World Health Organization, 2005, WHO declares TB an emergency in Africa, viewed.26 August 2005, from http://www.who.int/mediacentre/news/releases/2005/ africa_emergency/en/index.html; accessed 04 April 2013

World Health Organization, 2009, Global tuberculosis Control: Epidemiology, Strategy, Financing, pp. 6-33, World Health Organization, Geneva.

World Health Organization, 2010, Global Tuberculosis Control: WHO Report 2010, viewed 14 April 2013, from http://www.who.int/tb/publications/global_report/en/ 